\title{
$\alpha$-Tocopherol reduces oxidative stress in perinatal asphyxia
}

\section{Rashidul Karim and M. A. Mannan}

Department of Pediatrics, Bangabandhu Sheikh Mujib Medical University, Shahbag, Dhaka 1000, Bangladesh.

\begin{tabular}{|c|c|}
\hline \multicolumn{2}{|l|}{ Article Info } \\
\hline Received: & 13 December 2005 \\
\hline Accepted: & 11 January 2006 \\
\hline Available Online: & 3 January 2008 \\
\hline \multicolumn{2}{|c|}{ DOI: $10.3329 /$ bjp.v1i1.480 } \\
\hline \multicolumn{2}{|c|}{$\begin{array}{l}\text { Cite this article: } \\
\text { Karim R, Mannan MA. a-Tocopherol } \\
\text { reduces oxidative stress in perinatal } \\
\text { asphyxia. Bangladesh J Pharmacol. } \\
\text { 2006; 1: 5-9. }\end{array}$} \\
\hline
\end{tabular}

\begin{abstract}
Twenty asphyxiated neonates were studied by estimating reduced gluthathione (GSH) level in red blood cell (RBC) to assess the level of oxidative stress. Neonates were randomly divided into two groups. One group received a-tocopherol (10 mg/kg body weight) once orally daily for 5 days and other group received only vehicle. The mean $( \pm \mathrm{SD})$ value of GSH in RBC within 24 hours of age of asphyxiated neonates was $12.3 \pm 4.3 \mathrm{mg} / \mathrm{dL}$ in untreated group and $12.0 \pm 2.3 \mathrm{mg} / \mathrm{dL}$ in treated group. After 5 days of asphyxiated neonates (in a-tocopherol untreated group) the GSH level increased to $14.5 \pm$ $3.5 \mathrm{mg} / \mathrm{dL}$ whereas in asphyxiated neonates treated with a-tocopherol, it increased to $25.7 \pm 5.0 \mathrm{mg} / \mathrm{dL}$ indicating 5 days treatment with a-tocopherol among asphyxiated neonates caused approximately 2-fold increase in GSH level which was statistically significant $(p<0.001)$. This study suggests that $a-$ tocopherol may be useful to reduce the oxidative stress in patients of perinatal asphyxia.
\end{abstract}

\section{Introduction}

Perinatal asphyxia, all over the world, remains an important cause of perinatally acquired brain injury in full term infants. In developing countries, perinatal asphyxia appears to be more common. During perinatal asphyxia, hypoxia and ischemia cause primary neuronal injury because of cell necrosis (Hossman, 1983). Neonatal resuscitation results in oxygenation and reperfusion, which in turn, leads to delayed, or secondary neuronal injury. The mechanisms believed to be important in this secondary phase of neuronal injury include oxygen free radical production (McCord, 1985), intracellular calcium entry and apoptosis (Evans and Levene, 1999). Numerous studies have suggested that free radicals could have a key role in causing hypoxic ischemic damage to the brain, especially during the reoxygenation/reperfusion phase (Ogihara et al., 2003).

Vitamin $\mathrm{E}$ is a fat-soluble vitamin that exits in eight different forms, four tocopherols ( $\alpha_{-}, \beta-, \gamma^{-}$and $\left.\delta_{-}\right)$and four tocotrienols (also $\alpha-, \beta-, \gamma^{-}$and $\delta$-). $\alpha$-tocopherol is the name of the most active form of vitamin $E$ in humans. Vitamin E or tocopherol is a membrane bound, chain breaking anti-oxidant. Once lipid peroxidation is initiated, peroxyl radicals react with vitamin $\mathrm{E}$ instead of an adjacent fatty acid, thus terminating the process (Palmer and Vanucci, 1993).

Perinatal asphyxia is a leading cause of morbidity and mortality of neonates in our country. It is seen that infants with asphyxia have elevated oxidative stress, and leads to delay or secondary neuronal injury. This problem may cause death or subsequent severe neuro developmental disability/handicap in future. In the present study, administrating a-tocopherol acts as a free radicals scavenger to infants following perinatal asphyxia with primary aims of prevention of death or subsequent severe neurodevelopemental disability by reducing secondary neuronal injury from free radicals. 


\section{Materials and Methods}

\section{Chemical}

a-tocopherol was a gift from Square Pharmaceuticals Ltd (Bangladesh). DTNB was purchased from Sigma Chemicals (USA).

\section{Design and place of study}

This prospective study was conducted at the Department of Pediatrics (Neonatal unit), Bangabandhu Sheikh Mujib Medical University and Dhaka Medical College Hospital. The study was carried out from July 2004 to January 2005.

\section{Subjects}

A total number of 30 newborns were selected randomly of which 20 were asphyxiated neonates and the rest 10 were non-asphyxiated normal neonates. Asphyxiated neonates were equally divided into two groups. One group was supplemented with a-tocopherol and another group received vehicle only. Term neonates, who did not require respiratory support, were clinically stable, not suffering from perinatal asphyxia or sepsis, having no major congenital malformations were taken as the control.

All the cases of this study were infants, irrespective of male and female, having gestational age of 37 completed weeks to 42 weeks with the birth weight of more than 2,500 g, whose postnatal age were within 24 hours. Asphyxia neonataram was diagnosed by performing apgar score 3 or less at the end of 1st min of life, delayed onset of first cry, infants who required resuscitation with positive pressure ventilation to establish spontaneous respiration after birth and also showed overt clinical signs of asphyxia, such as hypotonia, apnea, non responsive to external stimuli, pallor and also bradycardia $(<80 / \mathrm{min})$. Any major congenital anomalies, neonatal sepsis, hemolytic disease or any other symptomatic hematologic disorders were excluded from the study.

\section{Study procedure}

After enrolment in this study relevant information from history, physical findings were recorded on a predesigned questionnaire form. The purpose and procedure of the study were explained to the parents and their consents were taken. a-tocopherol $10 \mathrm{mg} / \mathrm{kg}$ body weight/dose was given to 10 asphyxiated neonates as daily single dose in the morning for 5 days.
Under all precaution minimal $1 \mathrm{~mL}$ of blood samples were drawn from a peripheral vein. The blood was collected into heparinized tubes. Blood samples were drawn twice, within 24 hours of age and after 5 days of age.

\section{Laboratory procedure}

The amount of GSH in RBC was estimated spectrophotometrically by the method described elsewhere and expressed as $\mathrm{mg} / \mathrm{dL}$ of RBC (Beutler et al., 1963). In brief, $1 \mathrm{~mL}$ of heparinized blood was centrifuged at 4,000 rpm for $5 \mathrm{~min}$. Upper clear solution (plasma) was removed and erythrocytes were washed twice with phosphate buffer solution. $1 \mathrm{~mL}$ of TCA (tri-chloroacetic acid) was added, mixed thoroughly and again centrifuged for $5 \mathrm{~min}$ at 4,000 rpm. After centrifuged, $0.3 \mathrm{~mL}$ of clear fluid was taken into another test tube and $2 \mathrm{~mL}$ of buffer solution $\left(\mathrm{Na}_{2} \mathrm{HPO}_{4}\right)$ and $0.3 \mathrm{~mL}$ of DTNB reagent were added and mixed thoroughly. 40 $\mu \mathrm{L}$ of glutathione standard $(1 \mathrm{mg} / \mathrm{mL})$ solution and 210 $\mu \mathrm{L}$ of deionized water was taken in another test tube as standard, $2 \mathrm{~mL}$ of $\mathrm{Na}_{2}-\mathrm{HPO}_{4}$ and $0.3 \mathrm{~mL}$ of DTNB were also added in a test tube and mixed thoroughly, and a blank reagent obtained by replacing blood with deionized water, were included. The absorbance was measured by spectrophotometer (UV-Vis 1201, Shimadzu, Japan) at $412 \mathrm{~nm}$ after $20 \mathrm{~min}$ of adding DTNB solution. The absorbance of the reagent blank was subtracted from those of the standard and samples. Hematocrit value of whole blood was measured.

\section{Ethical consideration}

Prior to commencement of this study, the University Ethical Committee approved the research protocol. The aims and objectives of this study along with its procedure and benefits of this study were explained to the parents of the newborns in detail in easily and perfectly understandable language and informed consent was taken.

\section{Statistical analysis}

Collected data were checked for correctness and editing and coding was done and then data were entered into computer. The numerical data obtained from the study were analyzed and significance of difference was estimated by using the statistical methods. Data were analyzed by using computer based SPSS (Statistical Package for Social Science) program (version 11.5). Data were expressed in percentage, mean and standard deviation as applicable. Comparison between groups 
was done by unpaired student's t-test and paired t-test as applicable. Probability less than 0.05 was considered as significant.

\section{Results \\ GSH level in RBC according to causes of perinatal asphyxia}

It was evident that among the asphyxiated patients, frequent causes of perinatal asphyxia were obstructed labor $(55.0 \%)$ followed by eclampsia $(40.0 \%)$ and forcep delivery $(5.0 \%)$. The mean value of GSH in RBC of obstructed labor was $13.7 \pm 3.4 \mathrm{mg} / \mathrm{dL}$ and of eclampsia was $9.7 \pm 1.1 \mathrm{mg} / \mathrm{dL}$ and the mean difference was statistically significant $(\mathrm{p}<0.001)$.

\section{GSH level in RBC of normal and asphyxiated neonates}

The mean value of GSH in RBC of normal baby within 24 hours of age was $65.6 \pm 12.6 \mathrm{mg} / \mathrm{dL}$. But in asphyxiated neonates, it was reduced to $12.3 \pm 4.3 \mathrm{mg}$ / $\mathrm{dL}$ (a-tocopherol untreated group) and $12.0 \pm 2.3 \mathrm{mg}$ / $\mathrm{dL}$ (a-tocopherol treated group) respectively. Asphyxia reduced the level of GSH to 18.7 and $18.1 \%$ respectively. This difference was not statistically significant $(p>0.05)$. After 5 days of treatment with conventional therapy, the level of GSH increased from $12.3 \pm 4.3$ to $14.5 \pm 3.5 \mathrm{mg} / \mathrm{dL}(17.9 \%)$, which was not statistically significant $(p>0.05)$. On the other hand, asphyxiated baby treated with a-tocopherol increased the level of GSH from $12.0 \pm 2.3$ to $25.7 \pm 5.0 \mathrm{mg} / \mathrm{dL}(114.3 \%)$, which was statistically significant $(\mathrm{p}<0.001)$.

GSH improvement was found only $22.0 \%$ in asphyxiated neonates treated without a-tocopherol, whereas $39.1 \%$ improvement was evident in neonates treated with a-tocopherol compared to that of the normal neonates, which was considered as $100.0 \%$.

\section{Discussion}

Oxidative stress in vivo is a degenerative process caused by the overproduction and propagation of free radical reactions (Buonocore et al., 2001). Oxidative stress may be assessed by determining GSH, GSSG and antioxidant enzyme activities. Blood GSH/GSSG ratio may be an indicator of oxidative stress. Decrease in GSH and increase in GSSG reflects oxidative stress (Vento et al., 2003).
Table I

\begin{tabular}{|c|c|c|}
\hline \multicolumn{3}{|c|}{$\begin{array}{l}\text { The mean }( \pm \mathrm{SD}) \text { concentration of GSH in } \\
\text { RBC according to causes of perinatal asphyxia }\end{array}$} \\
\hline Causes & $\begin{array}{l}\text { GSH level }(\mathrm{mg} / \mathrm{dL}) \text { in } \mathrm{RBC} \\
\text { within } 24 \text { hours of age }\end{array}$ & $\begin{array}{c}\mathrm{p} \\
\text { value }\end{array}$ \\
\hline $\begin{array}{l}\text { Obstructed labor } \\
(\mathrm{n}=12)\end{array}$ & $13.7 \pm 3.4$ & $<0.001$ \\
\hline $\begin{array}{l}\text { Eclampsia } \\
(\mathrm{n}=8)\end{array}$ & $9.7 \pm 1.1$ & \\
\hline
\end{tabular}

aData are expressed as Mean $\pm \mathrm{SD} ; \mathrm{p}$ value reached from unpaired student's test

\section{Table II}

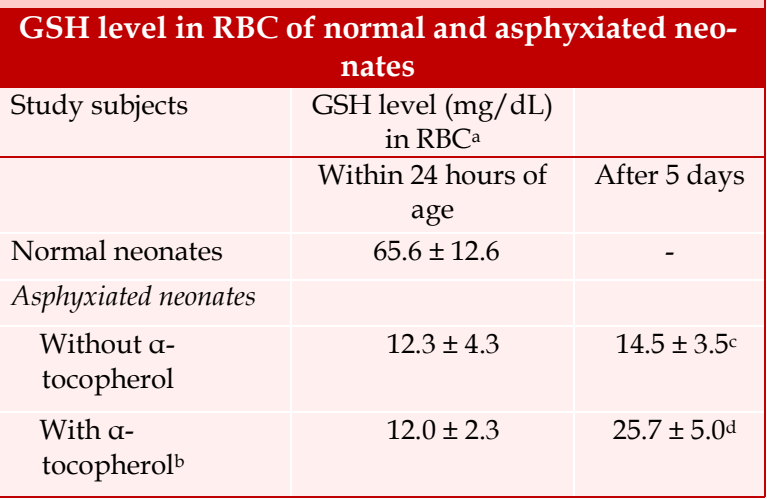

aData are expressed as Mean $\pm \mathrm{SD}$; bDose of a-tocopherol $10 \mathrm{mg} / \mathrm{kg}$ body weight/day for 5 days; ${ }^{c} p$ value $>0.05$; ${ }^{\mathrm{d}} \mathrm{p}$ value $<0.001$

In this study, degree of oxidative stress assayed in the newborns was performed by the measurement of GSH level only could the other parameters, as mentioned above, be measured in this study; stress conditions would definitely be better assessed. However, those measurements could not be done because of lack of necessary laboratory supports. This study showed the mean \pm SD concentration of GSH in RBC within 24 hours of age of normal baby was $65.6 \pm 12.6 \mathrm{mg} / \mathrm{dL}$.

But in asphyxiated neonates, it was reduced to $12.3 \pm$ $4.3 \mathrm{mg} / \mathrm{dL}$ (a-tocopherol untreated group) and $12.0 \pm$ $2.3 \mathrm{mg} / \mathrm{dL}$ (a-tocopherol treated group). This finding is consistent with the finding of Vento et al. (2003). This result suggests that newborn undergoes oxidative stress in perinatal asphyxia.

Perinatal asphyxia causes oxidative stress, can be explained by the observation of Ogihara et al. (2003). As they viewed, free radicals could have a key role in causing hypoxic-ischemic damage to the brain, especially during neonatal resuscitation results in reoxigenation and reperfusion phase in perinatal asphyxia Palmer, (1995) also explained that oxygen in paradoxi- 
cally the basis of most free radical species generated during reperfusion in perinatal asphyxia. During reperfusion of the previously ischemic brain, potentially damaging amounts of superoxide, hydrogen peroxide, and the even more reactive species such as the hydroxyl radical can be produced by free fatty acid and prostaglandin metabolism. During cerebral hypoxiaischemia, mitochondrial oxidative phosphorylation is impaired, causing ATP degradation and accumulation of hypoxanthine. Hypoxanthine is metabolized by xanthine oxidase to xanthine and uric acid in reactions that produce superoxide and hydrogen peroxide.

This study also showed the mean $( \pm \mathrm{SD})$ concentration of GSH in RBC after 5 days of age (a-tocopherol untreated group) was increased from $12.3 \pm 4.3 \mathrm{mg} / \mathrm{dL}$ to $14.5 \pm 3.5 \mathrm{mg} / \mathrm{dL}$ whereas in asphyxiated neonates treated with a-tocopherol, it was increased from $12.0 \pm$ $2.3 \mathrm{mg} / \mathrm{dL}$ to $25.7 \pm 5.0 \mathrm{mg} / \mathrm{dL}$ indicating 5 days treatment with a-tocopherol among asphyxiated neonates showed approximately 2-fold increased GSH level which was statistically significant $(\mathrm{p}<0.001)$. There is no comparable data regarding the role of a-tocopherol in the treatment of oxidative stress in perinatal asphyxia.

This favorable role of a-tocopherol in improving the oxidative stress conditions in perinatal asphyxia in the term newborns can be explained by the observations of Conner and Grisham (1996). As they viewed, Vitamin E or tocopherol is a membrane bound, chain breaking anti -oxidant may protect against reactive oxygen metabolites mediated cellular damage through free radical scavenging properties. It prevents the oxidation of low density lipoprotein, inhibits the propagation of lipid per -oxidation, and reduces toxicity associated with glutathione depleting agents Palmer and Vanucci (1993) also explained that vitamin $\mathrm{E}$ or tocopherol reduces the damaging effects of oxidative stress by once lipid peroxidation is initiated, peroxylradicals react with vitamin $\mathrm{E}$ instead of an adjacent fatty acid, thus terminating the process.

In this study, as a-tocopherol was administered, the condition of oxidative stress improved. Although GSH level rose significantly higher following supplementation of a-tocopherol in asphyxiated newborns yet the rise of GSH was not as high as that of a normal baby. Inappropriate duration a-tocopherol treatment could be one of the factors responsible for that. In this respect, another point of concern should be the use of lipid soluble a-tocopherol. It was reported previously, that the use of water-soluble a-tocopherol could improve its absorption from GI tract (Jansson et al., 1984). Because of nonavilability of the preparation of water-soluble atocopherol, we did not use that preparation.

\section{Conclusion}

Oxidative stress was observed in asphyxiated term neonates and a-tocopherol administration was seen to produce some favorable impact in the reduction of oxidative stress in perinatal asphyxia. Therefore, atocopherol may be useful to reduce the oxidative stress in patients of perinatal asphyxia.

This study recommends more prospective studies with bigger sample size to determine the duration of atocopherol therapy in asphyxiated newborn.

\section{Financial Support}

Self-funded

\section{Ethical Issue}

The study was approved be the Ethical Committee of Bangabandhu Sheikh Mujib Medical University.

\section{Conflict of Interest}

Authors declare no conflict of interest

\section{References}

Beutler E, Duron O, Kelly BM. Improved method for the determination of blood glutathione. J Lab Clin Med. 1963; 61: $882-88$.

Buonocore G, Perrone S, Bracci R. Free radicals and brain damage in the newborn. Biol Neonate. 2001; 79: 180-86.

Conner EM, Grisham MB. Inflammation, free radicals and antioxidants. Nutrition 1996; 12: 274-77.

Evans DJ, Levene MI. Hypoxic-ischemic injury. In: Textbook of neonatology. Rennie JM, Roberton NRC (eds). $3^{\text {rd }}$ edi. London, Churchill Livinstone, 1999, pp 1233-34.

Gitto E, Reiter RJ, Karbownik M, Tan DX, Gitto P, Barberi $\mathrm{S}$, Barberi I. Causes of oxidative stress in the pre- and perinatal period. Biol Neonate. 2002; 81: 146-57.

Hossmann KA. Neuronal survival and revival during and after cerebral ischemia. Am J Emerg Med. 1983; 1: 191-97.

Jansson L, Lindroth M, Tyopponen J. Intestinal absorption of vitamin E in low birth weight infants. Acta Paediatr Scand. 1984; 73: 329-32.

McCord JM. Oxygen derived free radicals in post-ischemic tissue injury. N Engl J Med. 1985; 312: 159-63.

Ogihara T, Hirano K, Ogihara H, Misaki K, Hiroi 
M, Morinobu T, Kim HS, Ogawa S, Ban R, Hasegawa M, Tamai H. Non-protein bound transition metals and hydroxyl radical regeneration in cerebrospinal fluid of newborn infants with hypoxic ischemic encephalopathy. Pediatr Res. 2003; 53: 594-99.

Palmer C, Vannucci RC. Potential new therapies for perinatal cerebral hypoxia ischemia. Clin Perinatol. 1993; 20: 411-32.

Palmer C. Hypoxic ischaemic encephalopathy (Therapeutic approaches aganist microvascular injury, and role of Neutrophils, PAF, and free radicals). Clin Perinatol. 1995; 22: 481517. 